Purdue University Purdue e-Pubs

2006

\title{
Analysis and Prediction of Constriction Resistance between Coated Surfaces
}

\author{
C. T. Merril \\ S V. Garimella \\ Purdue University, sureshg@purdue.edu
}

Follow this and additional works at: http://docs.lib.purdue.edu/coolingpubs

Merril, C. T. and Garimella, S V., "Analysis and Prediction of Constriction Resistance between Coated Surfaces" (2006). CTRC Research Publications. Paper 288.

http://docs.lib.purdue.edu/coolingpubs/288

This document has been made available through Purdue e-Pubs, a service of the Purdue University Libraries. Please contact epubs@purdue.edu for additional information. 


\title{
Analysis and Prediction of Constriction Resistance between Coated Surfaces"
}

\author{
Christine T. Merrill and Suresh V. Garimella ${ }^{\dagger}$ \\ Cooling Technologies Research Center \\ School of Mechanical Engineering, Purdue University \\ West Lafayette, Indiana 47907-1288
}

\section{$\underline{\text { Introduction }}$}

The resistance to heat flow encountered at the interface between two rough surfaces is a pervasive problem in thermal design. This phenomenon of contact resistance is important in electronics, aerospace and heat exchanger applications in which efficient heat removal is essential $^{1,2}$. Due to the microscopically rough nature of real engineering surfaces, only $1-2 \%$ of the nominal surface area is in actual contact ${ }^{3}$. An interstitial gas or vacuum fills the remaining gaps between these surfaces. The heat flow from one surface to the other is greatly constricted to flow through only the contacting asperities. To understand the flow of heat across the contact, it is necessary to understand the constriction resistance occurring on the microscale.

Constriction resistance is defined as the ratio of the additional temperature drop due to constriction to the rate of heat flow through the interface. Carslaw and Jaeger ${ }^{4}$ analytically determined the constriction resistance for a half-space. However, the half-space approximation is a poor approximation for actual surfaces in contact. Mikic and Rohsenow ${ }^{5}$ considered the heat as flowing through heat flux columns (semi-infinite cylinders) which terminate in a small contact radius. They showed that the constriction resistance for this case can be related to the resistance of a half space by a constriction alleviation factor, $\mathrm{F}$.

\footnotetext{
* Submitted for possible publication as a Technical Note in AIAA Journal of Thermophysics and Heat Transfer, December 2004, and in revised form March 2005.

$\dagger$ Author to whom correspondence should be addressed: 765-494-5621; 765-494-0539 (FAX); sureshg@purdue.edu
} 
Olsen et al. ${ }^{6}$ proposed that an asperity on a real surface is best modeled as a cylinder terminating in the frustum of a cone. Using a finite difference conduction analysis of this geometry, the effects of contact radius, contact angle, and substrate conductivity on constriction resistance were explored. Black et al. ${ }^{7}$ refined this model and calculated constriction resistance over a wide range of parameters for bare contacts. A generalized equation suitable for computer implementation was developed by performing a non-linear least squares fit to the numerical data. Singhal et al. ${ }^{8}$ used this equation in conjunction with a surface deformation model for bare surfaces to predict the contact resistance between real metallic surfaces.

For the mitigation of contact resistance, one or more of the mating surfaces is often coated with a conductive and malleable material such as tin or silver. The present work aims to extend the work of Black et al. ${ }^{7}$ to investigate constriction resistance in the presence of thin metallic coatings. A wide range of parameters is considered and a generalized correlation equation proposed for the constriction resistance across coated joints. This equation can be incorporated into computational models such as that of Singhal et al. ${ }^{8}$ for predicting contact resistance across flat, coated metal surfaces.

\section{$\underline{\text { Numerical Model and Analysis }}$}

A two-dimensional, axisymmetric model of a cylinder terminating in the frustum of a cone was used to represent a single contacting asperity, as illustrated in Figure 1. As shown in the figure, $a$ represents the contact spot diameter, while $b$ is the diameter of the heat flux tube. The thickness of the coating is denoted by $t$, and $\theta$ represents the contact angle. The coating thickness is considered to be uniform over the asperity. The thermal conductivities of the coating, substrate, and interstitial gas are denoted by $\mathrm{k}_{\mathrm{c}}, \mathrm{k}_{\mathrm{g}}$, and $\mathrm{k}_{\mathrm{s}}$, respectively. The contact 
diameter and coating thickness were normalized by the flux tube diameter to create the nondimensional parameters $a / b$ and $t / b$. The thermal conductivities of the coating and interstitial gas were likewise normalized by the thermal conductivity of the substrate material, $\mathrm{k}_{\mathrm{c}} / \mathrm{k}_{\mathrm{s}}$ and $\mathrm{kg}_{\mathrm{g}} / \mathrm{k}_{\mathrm{s}}$. The grid generation package GAMBIT $^{9}$ was used to generate an unstructured grid for each geometry, including the asperity, coating, and interstitial gas. The length, L, of each cylinder was four times as long as the cylinder diameter. This length was shown by Black et al. ${ }^{7}$ to be sufficient for a semi-infinite cylinder assumption. Each of these meshes contained approximately 5000 cells, and was more refined in the area of the contact, where the greatest constriction of heat flow is expected. The boundary conditions imposed are also described in Figure 1. Adiabatic conditions are prescribed along the axis of symmetry as well as the outside edge of the cylinder. The top surface is held at a constant temperature of $400 \mathrm{~K}$, while the bottom surface is at $300 \mathrm{~K}$. In addition, radiation through the gas gap is permitted, and accounted for as described by Olsen et al. ${ }^{6}$ For including the radiation contribution, an emissivity value of $\varepsilon=0.05$ was used for the electroplated metal surfaces. All other participating surfaces in the domain were assumed to have an emissivity of 1 to model them as reradiating surfaces. These boundary conditions induce a heat flow from the top of the cylinder toward the bottom. The commercial software package FLUENT ${ }^{10}$ was used in solving this conduction problem. The heat flow, q, through the cylinder was used to compute the constriction resistance from the definition given in Figure 1

$$
R=\frac{\Delta T}{q}
$$

While the actual temperature at the contact surface, $\mathrm{T}_{0}$, is known from the imposed boundary condition, the unconstricted temperature $\mathrm{T}^{*}$ is computed by considering unconstricted heat flow 
under similar boundary conditions. $\mathrm{T}^{*}$ represents the temperature that would be seen on the surface of the contact spot in the absence of any constriction. Using Fourier's law,

$$
T^{*}=T_{b}-\left(\frac{L-t}{k s}+\frac{t}{k c}\right) \frac{q}{A_{c}}
$$

Thus, the constriction resistance can be computed as

$$
R=\frac{\left(T_{b}-\left(\frac{L-t}{k s}+\frac{t}{k c}\right) \frac{q}{A_{c}}-T_{0}\right)}{q}
$$

Energy conservation was assessed for the computed results, and the heat flow mismatch between top and bottom surfaces was found to be less than $1 \%$ for all cases considered. In addition, when the number of grids was more than tripled, the heat flow rates changed by less than $1 \%$, confirming grid independence of the results. The length of the cylinder chosen was shown to satisfy the semi-infinite cylinder approximation by noting that the heat flux across the top surface was spatially uniform ${ }^{6}$. Black et al. ${ }^{7}$ performed a number of other checks on a similar but uncoated geometry to justify the modeling method.

A total of 3072 cases were investigated, covering a wide range of variation for the governing parameters: $0.01 \leq \mathrm{a} / \mathrm{b} \leq 0.1,0.1 \leq \mathrm{t} / \mathrm{b} \leq 0.5,0.0175 \mathrm{rad} \leq \theta \leq 0.628 \mathrm{rad}, 0.167 \leq \mathrm{k}_{\mathrm{c}} / \mathrm{k}_{\mathrm{s}}$ $\leq 30.667$, and $1.01 \times 10^{-4} \leq \mathrm{k}_{\mathrm{g}} / \mathrm{k}_{\mathrm{s}} \leq 1.63 \times 10^{-3}$. These parameter ranges were chosen to encompass values for a wide variety of real surfaces. Profile scan data were used to determine appropriate values for $\mathrm{a} / \mathrm{b}$ and $\theta$. Bead-blasted metals with a roughness between 1 and $15 \mu \mathrm{m}$ were used in these scans. Values for thermal conductivity ratios were chosen based on $\mathrm{k}_{\mathrm{g}}$ being held constant at $0.242 \mathrm{~W} / \mathrm{mK}, \mathrm{k}_{\mathrm{s}}$ being varied between 40 and $460 \mathrm{~W} / \mathrm{mK}$, and $\mathrm{k}_{\mathrm{c}}$ being varied between 15 and $150 \mathrm{~W} / \mathrm{mK}$, representing thermal conductivities of metals commonly used in applications where contact resistance is important. 
This work was validated by comparing the predicted results against those obtained by Black et at. ${ }^{7}$ for a similar geometry, but with no coating. Results from the present model for either $\mathrm{t} / \mathrm{b}=0$ or $\mathrm{k}_{\mathrm{c}} / \mathrm{k}_{\mathrm{s}}=1$ (which correspond to an uncoated asperity) were compared with those in Black et al., and found to agree to within less than $1 \%$.

\section{$\underline{\text { Results and Discussion }}$}

Representative numerical predictions obtained from the present work are presented in Figures 2 and 3. All the results are non-dimensionalized. Figure 2 shows the effect of the thickness ratio, $\mathrm{t} / \mathrm{b}$, on constriction resistance, $\mathrm{R}$. It is apparent that the thickness ratio is not a major parameter in constriction resistance if $\mathrm{k}_{\mathrm{c}} / \mathrm{k}_{\mathrm{s}}>1$. In cases where the conductivity of the substrate is greater than that of the coating, the thickness of the coating plays a more important, detrimental role, as would be expected. Although $\mathrm{R}$ decreases slightly as $\mathrm{t} / \mathrm{b}$ increases for $\mathrm{k}_{\mathrm{c}} / \mathrm{k}_{\mathrm{s}}>$ 1 , the decrease is very small compared to the effect of the other parameters. A decrease in $\mathrm{R}$ is desirable because the total contact resistance is a function of the summation of constriction resistances for each individual contact on the surface. Thus, a constriction resistance value near zero implies better heat flow. Black et al. ${ }^{7}$ showed that typical constriction resistance values for uncoated rough metallic surfaces are less than $0.2 \mathrm{~K} / \mathrm{W}$, although much larger values can result for very rough geometries, or for materials with very poor thermal conductivity.

In Figure 3, $\mathrm{R}$ is shown as a function of $\mathrm{k}_{\mathrm{c}} / \mathrm{k}_{\mathrm{s}}$ as a number of different parameters are varied. The constriction resistance drops off quickly as the value of the conductivity ratio is increased. Also, as this ratio increases, the effect of other parameters on $\mathrm{R}$ diminishes. The effect of the contact radius ratio, a/b, can also be observed in this graph. A larger contact radius ratio tends to result in significantly lower resistances than smaller contact radius ratios. It is 
clear that the actual area of contact is perhaps the most important parameter determining contact resistance. Compared to $\mathrm{a} / \mathrm{b}$ or $\mathrm{k}_{\mathrm{c}} / \mathrm{k}_{\mathrm{s}}$, parameters $\mathrm{k}_{\mathrm{g}} / \mathrm{k}_{\mathrm{s}}$ and $\mathrm{t} / \mathrm{b}$ have a smaller influence on constriction resistance. Black et al. ${ }^{7}$ studied the effect of $\mathrm{k}_{\mathrm{g}} / \mathrm{k}_{\mathrm{s}}, \theta$, and $\mathrm{a} / \mathrm{b}$ for a non-coated (bare) joint. The presence of a coating is shown in this work to have little change in the effect of these parameters on the constriction resistance.

Results from the present work are also compared against the constriction resistance model of Antonetti and Yovanovich. ${ }^{11}$ Table 1 shows sample comparisons from the two models. The two sets of results generally match well, with the greatest differences seen when $\theta$ is small. This illustrates the effect of the inclusion of asperity slope on the constriction resistance.

Because the present work takes into account the effect of asperity slope and conduction through the interstitial gas, very rough surfaces are better represented with the current model. Inclusion of radiation in the current model also accounts for a small part of the difference between the predicted results and those of Antonetti and Yovanovich.

Using a nonlinear least-squares regression, the computed constriction resistance values were fitted to a general equation that can be used for computer implementation of these results:

$$
\begin{array}{cc}
R_{\text {constriction }}= & \frac{1}{4 k_{s} a}\left(1.91 \theta^{\Psi_{1}}\right) \kappa^{\Psi_{2}}\left(1-\frac{a}{b}\right)^{\Psi_{3}}\left(1-\frac{t}{b}\right)^{\Psi_{4}}\left(2.49 e^{-1.91 \mathrm{~K}}+0.38 e^{-0.11 \mathrm{~K}}\right) \\
\Psi_{1}=\kappa^{-0.039}-0.748 & \Psi_{3}=\frac{-1.6}{(1-t / b)^{1.96} \theta^{0.17}} \\
\Psi_{2}=\frac{3.69(1-a / b)^{51.86}(1-t / b)^{0.01}}{\mathrm{~K}^{0.55}} & \Psi_{4}=\frac{0.34 \mathrm{~K}^{0.30}}{(1-a / b)^{15.88}}-0.41
\end{array}
$$

The two conductivity ratios used in this equation are $\mathrm{K}=\mathrm{k}_{\mathrm{c}} / \mathrm{k}_{\mathrm{s}}$ and $\kappa=\mathrm{k}_{\mathrm{s}} /\left(\mathrm{k}_{\mathrm{s}}+1000 \mathrm{k}_{\mathrm{g}}\right)$. The parameter $\kappa$ was introduced in Black et al. ${ }^{7}$ to obtain physically realistic values in the case where 
$\mathrm{k}_{\mathrm{g}}$ approaches zero, such as in a vacuum. This correlation equation is expected to be valid for the parameter ranges investigated, which were specified earlier. This equation gathers $79 \%$ of the results to within $30 \%$ of the actual value, while $56 \%$ of the results are matched to within $15 \%$. The largest errors occur when $\mathrm{R}$ is very small, and the error decreases as $\mathrm{R}$ increases. The equation exhibits physically realistic trends of variation with the governing parameters. For example, as a/b approaches 1 , or $\theta$ approaches 0 , the constriction resistance approaches 0 . In other words, as the contact area increases, constriction is eliminated. As a/b decreases to 0 , the constriction resistance becomes infinite, which is as expected if there is no contact between two surfaces. The equation also captures the correct effects for $t / b$ within the stated range of validity.

\section{$\underline{\text { Conclusions }}$}

A model for constriction resistance between two rough, coated surfaces has been developed. A coated semi-infinite cylinder terminating in the frustum of a cone is analyzed. The effect of five different geometrical and material property parameters has been explored, and a generalized correlation equation has been developed. In ongoing work, the results of this modeling effort are being integrated with a surface deformation analysis to generate a predictive model for the thermal contact resistance at the interface between two metallic, coated surfaces. Experiments are also underway that will generate a comprehensive database of contact resistance values for coated surfaces, and will be used to validate the predictive model.

\section{$\underline{\text { Acknowledgements }}$}

The first author was supported under a National Science Foundation Graduate Research Fellowship. The authors also acknowledge financial support from members of the Cooling 
Technologies Research Center (www.ecn.purdue.edu/CTRC), a National Science Foundation

Industry/University Cooperative Research Center at Purdue University.

\section{References}

${ }^{1}$ Yovanovich, M.M. and Antonetti, V.W., "Application of thermal contact resistance theory to electronic packages," Advances in Thermal Modeling of Electronic Components, Vol. 1, 1988, pp. $79-128$.

${ }^{2}$ Madhusudana, C.V., Thermal Contact Conductance, Springer-Verlag, New York, 1996.

${ }^{3}$ Bowden, F.P. and Tabor, D., The Friction and Lubrication of Solids, Oxford University Press, London, 1950, pp. 20-32.

${ }^{4}$ Carslaw, H.S. and Jaeger, J.C., Conduction of Heat in Solids, 2nd edition, Clarendon Press, Oxford, 1959, pp. 214-217.

${ }^{5}$ Mikic, B.B. and Rohsenow, W.M., 1966, “Thermal contact resistance," Mechanical Engineering Department Report No. DSR 74542-41, MIT, Cambridge, MA.

${ }^{6}$ Olsen, E.L., Garimella, S.V. and Madhusudana, C.V., "Modeling of constriction resistance in coated joints," AIAA Journal of Thermophysics and Heat Transfer, Vol. 16, 2002, pp. 207-216.

${ }^{7}$ Black, A.F., Singhal, V. and Garimella, S.V., "Analysis and prediction of constriction resistance for contact between rough engineering surfaces," AIAA Journal of Thermophysics and Heat Transfer, Vol. 18, 2004, pp. 30-36.

${ }^{8}$ Singhal, V. and Garimella, S.V., "Prediction of thermal contact conductance by surface deformation analysis," Proceedings of the International Mechanical Engineering Congress and Exposition, New York, IMECE2001/HTD-24376, pp. 1-9.

${ }^{9}$ Fluent Inc., "Gambit 2.0 User's Guide," Lebanon, NH, Fluent Inc, 2002.

${ }^{10}$ Fluent Inc., "Fluent 6.0 User's Guide," Lebanon, NH, Fluent Inc, 2000.

${ }^{11}$ Antonetti, V.W. and Yovanovich, M.M., "Enhancement of thermal contact conductance by metallic coatings: Theory and experiment," Journal of Heat Transfer, Vol. 107, pp. 513-519. 
Table 1. Comparison of predicted values of constriction resistance against those from the Antonetti and Yovanovich model.

\begin{tabular}{|cccc|}
\hline $\mathrm{a} / \mathrm{b}$ & $\mathrm{t} / \mathrm{b}$ & $\begin{array}{c}\text { Present } \\
\text { Work }\end{array}$ & $\begin{array}{c}\text { Antonetti and } \\
\text { Yovanovich }\end{array}$ \\
\hline 0.1 & 0.5 & 0.0046 & 0.0047 \\
\hline 0.1 & 0.34 & 0.0052 & 0.0048 \\
\hline 0.075 & 0.26 & 0.0155 & 0.0134 \\
\hline
\end{tabular}

Table 2. The effect of asperity slope on constriction resistance for $a / b=0.025$ and $t / b=0.1$.

\begin{tabular}{|c|cc|}
\multicolumn{2}{|c|}{ Antonetti and Yovanovich } & 0.0942 \\
& $\theta=1$ & 0.0494 \\
Present & $\theta=18$ & 0.0906 \\
Work & $\theta=24$ & 0.0949 \\
& $\theta=36$ & 0.1054 \\
\hline
\end{tabular}

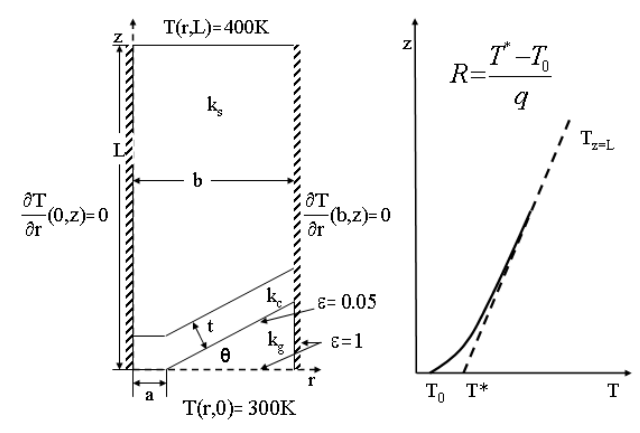

Figure 1. Geometry and boundary conditions used to model constriction resistance in a coated asperity. The constricted and unconstricted temperature profiles are used to compute the constriction resistance. 


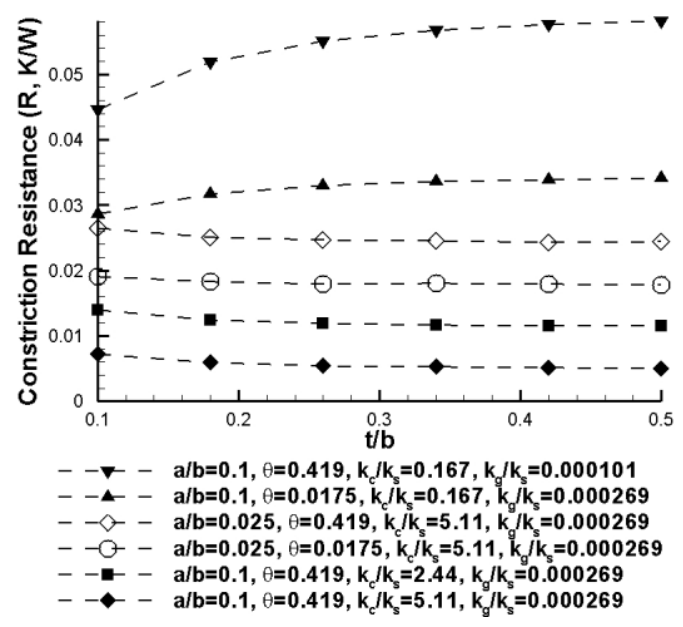

Figure 2. Constriction resistance as a function of coating thickness ratio under different conditions.

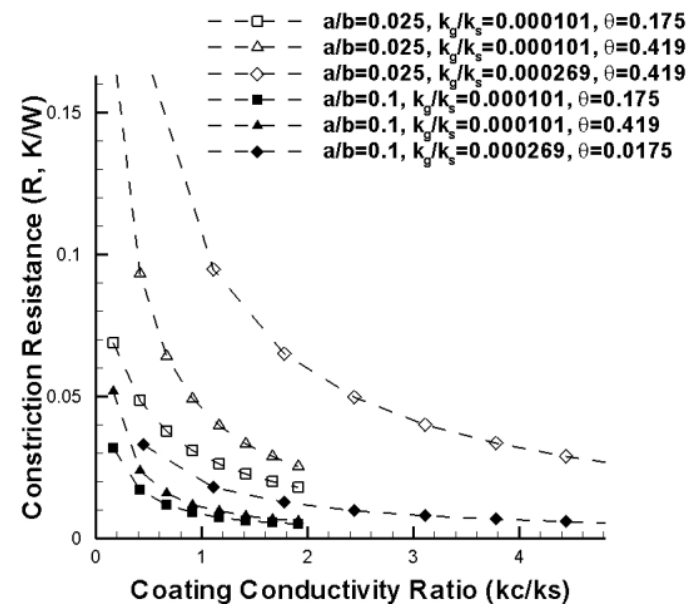

Figure 3. Constriction resistance as a function of coating conductivity ratio under different conditions. The coating thickness ratio is held constant at $t / b=0.18$ 